\title{
Neonatal Resuscitation with an Intact Cord: Current and Ongoing Trials
}

\author{
Anup C. Katheria ${ }^{1,2}$ \\ 1 Sharp Mary Birch Hospital for Women \& Newborns, San Diego, CA 92123, USA; anup.katheria@sharp.com \\ 2 School of Medicine, Loma Linda University, Loma Linda, CA 92350, USA
}

Received: 13 March 2019; Accepted: 19 April 2019; Published: 22 April 2019

\begin{abstract}
Premature and full-term infants are at high risk of morbidities such as intraventricular hemorrhage or hypoxic-ischemic encephalopathy. The sickest infants at birth are the most likely to die and or develop intraventricular hemorrhage. Delayed cord clamping has been shown to reduce these morbidities, but is currently not provided to those infants that need immediate resuscitation. This review will discuss recently published and ongoing or planned clinical trials involving neonatal resuscitation while the newborn is still attached to the umbilical cord. We will discuss the implications on neonatal management and delivery room care should this method become standard practice. We will review previous and ongoing trials that provided respiratory support compared to no support. Lastly, we will discuss the implications of implementing routine resuscitation support outside of a research setting.
\end{abstract}

Keywords: delayed cord clamping; resuscitation; newborn; premature infants

\section{Introduction}

There is a large body of evidence that has now demonstrated that delayed cord clamping (DCC) has benefits for term and preterm infants. [1-3]. These benefits include reductions in morbidities such as intraventricular hemorrhage (IVH) and mortality in preterm infants and improved developmental scores at 4 years of age in term infants. One important group that has not been included is the nonbreathing, non-vigorous infant. It may be important to determine whether an infant has started to breathe before the umbilical cord is clamped. This has been suggested in a number of small studies where infants who breathed had less blood retained in the placenta and higher hematocrits $[4,5]$. Preterm infants also take longer to establish breathing than term newborns, placing greater emphasis on the determination of breathing before the cord is clamped [6,7]. One epidemiologic study suggested that term newborns that take longer to breathe after their cord is clamped have a higher rate of admission to the NICU and increased mortality [8]. Another observational study of preterm infants demonstrated higher rates of IVH and bronchopulmonary dysplasia (BPD) in infants that were not breathing during delayed cord clamping [9].

Animal work suggests that positive pressure ventilation in anesthetized preterm lambs during DCC eliminated fluctuations in cardiac output and cerebral blood flow compared to early cord clamping [10]. One hypothesis is that in response to the lungs inflating, the placenta provides the additional blood supply needed to fill the pulmonary vascular bed. The venous return from the lungs then enters the left atrium and provides the needed preload for left ventricular output and cerebral perfusion. The result is increased blood volume and stable perfusion, particularly to the brain [11]. This is critical particularly in preterm infants that have limited cerebral autoregulation (Figure 1). 


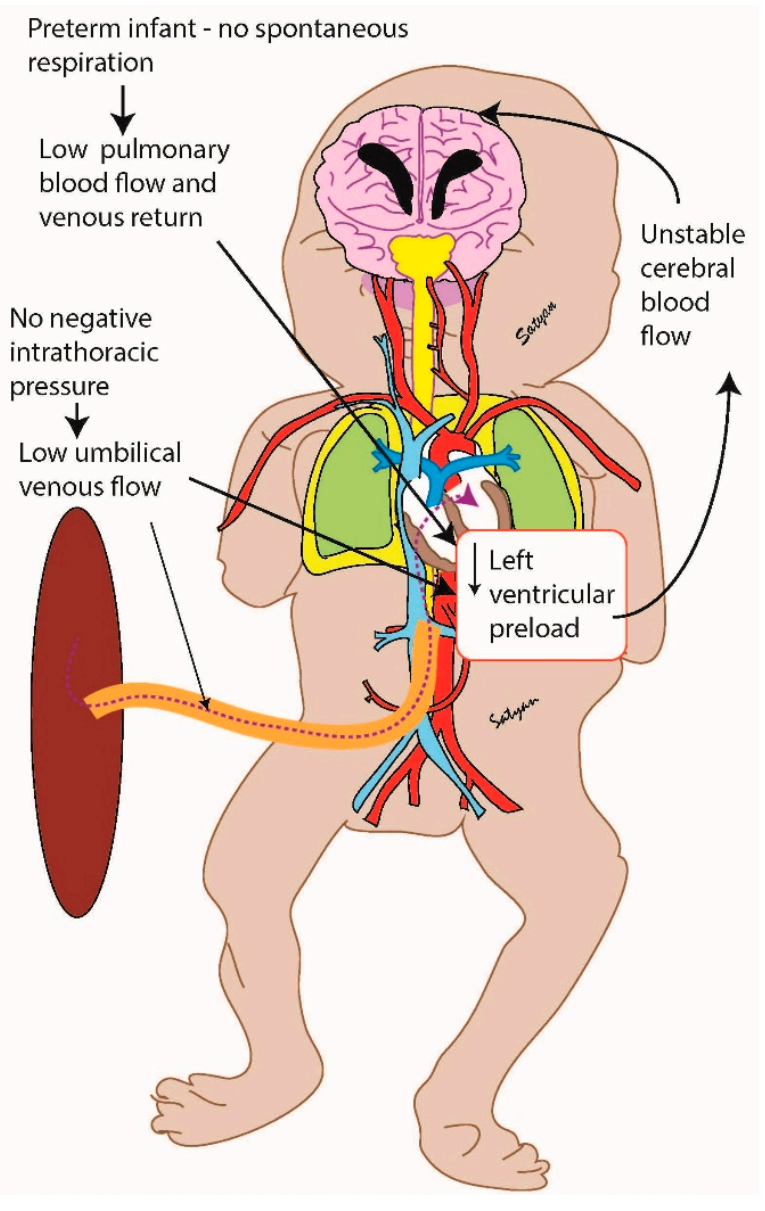

Figure 1. Preterm infant without spontaneous respirations.

The challenge with translating physiology into evidence lies with the ability to include infants that require resuscitation into randomized controlled trials of delayed cord clamping. Various trials have had significant protocol violations, including the largest trial (Australian Placental Transfusion Study, APTS, $n=1500$ ) in which over 25 percent of infants that were randomized to delayed cord clamping actually received immediate cord clamping [2]. The major reason cited was due to concerns for the infant. Unfortunately, infants that need greater resuscitation are more likely to have greater morbidity including IVH and death [12]. Despite a number of smaller trials and animal data suggesting DCC could reduce IVH, the APTS trial showed no difference in IVH. Facilitating a placental transfusion in this population could have greater benefits than only the included vigorous preterm infants that have been included in previous trials. Respiratory support, in the form of positive pressure ventilation or continuous positive airway pressure (CPAP) could be given to all infants undergoing DCC or only to those who fail to establish spontaneous respirations. Alternatively, more invasive strategies such as endotracheal intubation may be provided.

There are several completed and ongoing trials investigating ventilation with an intact umbilical cord. Since there is significant heterogeneity with respect to the population (term versus preterm) and feasibility studies, we will discuss these in their respective sections.

\section{Feasibility Studies in Preterm Infants}

There are several recently completed feasibility trials involving resuscitation with an intact cord. The first pilot study by Winter et al. sought to determine whether ventilatory support with continuous positive airway pressure or positive pressure ventilation was feasible during $90 \mathrm{~s}$ of DCC in infants at 24 to 32 weeks gestation [13]. A total of 29 infants were enrolled and all completed the protocol without any adverse outcomes. 
Blank et al. recently completed a feasibility trial using a colorimetric $\mathrm{CO}_{2}$ detector to manage when cord clamping was performed [14]. The trial enrolled 44 infants and the median time to cord clamping was $150 \mathrm{~s}$ and $138 \mathrm{~s}$ in vigorous and non-vigorous infants, respectively.

Knol et al. completed a feasibility study to demonstrate whether infants $<35$ weeks could be placed on a specialized bed equipped with respiratory function monitoring long enough to achieve physiological targets before having cord clamping. These targets were set as a heart rate $>100 \mathrm{bpm}$, spontaneous breathing on continuous positive airway pressure with tidal volumes $>4 \mathrm{~mL} / \mathrm{kg}$, and $\mathrm{SpO}_{2} \geq 25$ th percentile and fraction of inspired oxygen $\left(\mathrm{FiO}_{2}\right)<0.4$. They were able to achieve these targets in 33/37 infants. The median time to cord clamping was $4 \mathrm{~min}$ and $23 \mathrm{~s}$ after birth [15].

Pratesi et al. completed a pilot feasibility study comparing 3 min delay with resuscitation when needed to intact umbilical cord milking four times. Infants with delayed cord clamping had a higher 5 min Apgar, but a lower admission temperature [16].

\section{Completed Randomized Controlled Trials}

To date, there are three randomized controlled trials involving resuscitation with an intact cord (Table 1). The first trial by Duley et al. randomized infants to immediate cord clamping $(<20 \mathrm{~s})$ or at least $2 \mathrm{~min}$ of delayed cord clamping with resuscitation when needed [17]. The median gestational age was 28 weeks. There was no difference in any outcomes, but a trend for decreased mortality with delayed cord clamping emerged. However, only 59 percent of the infants randomized to delayed cord clamping reached the 2-minute time point.

Table 1. Completed trials of neonatal resuscitation with an intact cord.

\begin{tabular}{|c|c|c|c|c|c|c|}
\hline Study & $n$ & GA (weeks) & Intervention & $\begin{array}{l}\text { Time of Cord } \\
\text { Clamping, } \\
\text { Control Arm }\end{array}$ & $\begin{array}{c}\text { Time of Cord } \\
\text { Clamping } \\
\text { Intervention Arm }\end{array}$ & $\begin{array}{l}\text { Clinical } \\
\text { Outcome }\end{array}$ \\
\hline $\begin{array}{l}\text { Duley et al., } \\
2017 \text { [17] }\end{array}$ & 137 & $23-31$ & $\begin{array}{l}\text { Resuscitation } \\
\text { if needed }\end{array}$ & $20 s$ & $120 \mathrm{~s}$ & No difference \\
\hline $\begin{array}{l}\text { Katheria et al., } \\
2016 \text { [18] }\end{array}$ & 154 & $23-31$ & $\begin{array}{l}\mathrm{CPAP} \text { and PPV } \\
\text { if apneic }\end{array}$ & $60 \mathrm{~s}$ & $60 \mathrm{~s}$ & No difference \\
\hline $\begin{array}{l}\text { Katheria et al., } \\
2018 \text { [19] }\end{array}$ & 60 & $37-42$ & $\begin{array}{l}\text { Resuscitation } \\
\text { if needed }\end{array}$ & $60 \mathrm{~s}$ & $3-5 \mathrm{~min}$ & No Difference \\
\hline
\end{tabular}

Our group performed a randomized trial and compared initiation of ventilation immediately after birth compared to no ventilation at all for $60 \mathrm{~s}$ with an intact cord in preterm infants $<32$ weeks $(n=150)$ [18]. We also conducted a second randomized clinical trial in term babies at risk for resuscitation $(n=60)$, comparing resuscitation with an intact cord to usual care [19]. Neither study found any clinical differences. However, in our preterm trial, over 90 percent of infants began breathing before $60 \mathrm{~s}$ with gentle stimulation in both groups. If spontaneous ventilation in humans mimics the improved and stable hemodynamics found in the animal model, this may explain why positive pressure ventilation had no value.

\section{Ongoing Randomized Controlled Trials}

There are three ongoing trials involving resuscitation with an intact cord (Table 2). The first trial, VentFirst (NCT02742454, proposed $n=940$ ) aims to determine whether ventilation during delayed cord clamping of up to $120 \mathrm{~s}$ reduces the incidence of intraventricular hemorrhage compared to delayed cord clamping with no respiratory support for $30 \mathrm{~s}$ in non-breathing infants or $60 \mathrm{~s}$ in spontaneously breathing infants of 23-28 +6 weeks gestation at delivery. The trial currently has about $n=200$ infants (personal communication) with an expected completion of June 2023. 
Table 2. Ongoing or planned trials of neonatal resuscitation .

\begin{tabular}{|c|c|c|c|c|c|c|}
\hline Study & Proposed N & GA (weeks) & Intervention & $\begin{array}{l}\text { Time of Cord } \\
\text { Clamping, } \\
\text { Control Arm }\end{array}$ & $\begin{array}{c}\text { Time of Cord } \\
\text { Clamping } \\
\text { Intervention Arm }\end{array}$ & Primary Outcome \\
\hline VentFirst & 940 & $23-28$ & CРAP 30-120 s & $30-60 \mathrm{~s}$ & $120 \mathrm{~s}$ & IVH \\
\hline Nep-Cord 3 & 231 & $37-41$ & $\begin{array}{l}\text { Resuscitation } \\
\text { if needed }\end{array}$ & $<60 \mathrm{~s}$ & $180 \mathrm{~s}$ & $\begin{array}{c}\mathrm{SpO} 2, \mathrm{HR} \text {, and } \\
\text { Apgar scores in first } \\
10 \mathrm{~min}\end{array}$ \\
\hline Baby DUCC & 120 & $32-41$ & $\begin{array}{l}\text { Resuscitation } \\
\text { if needed }\end{array}$ & $\begin{array}{l}\text { Immediate cord } \\
\text { clamping } \\
\text { (duration not } \\
\text { specified) }\end{array}$ & $\begin{array}{l}\text { Until } 1 \text { minute } \\
\text { after } \mathrm{CO}_{2} \text { detector } \\
\text { change or } 5 \mathrm{~min}\end{array}$ & $\begin{array}{l}\text { Heart Rate at } 60 \text { and } \\
\qquad 120 \mathrm{~s}\end{array}$ \\
\hline $\mathrm{ABC} 2$ & 660 & $24-31$ & $\begin{array}{l}\text { Resuscitation } \\
\text { if needed }\end{array}$ & $30-60 \mathrm{~s}$ & $\begin{array}{c}\text { Until stable } \\
\text { (approx. } 4 \text { min) }\end{array}$ & $\begin{array}{c}\text { Intact Survival } \\
\text { (survival without } \\
\text { grade } 2 \text { ivh or nec) }\end{array}$ \\
\hline $\begin{array}{l}\text { Nevill and } \\
\text { Meyers }\end{array}$ & 120 & $23-31$ & $\begin{array}{l}\text { Start CPAP and } \\
\text { or PPV at } 15 \mathrm{~s} \\
\text { until } 60 \mathrm{~s}\end{array}$ & $60 \mathrm{~s}$ & $60 \mathrm{~s}$ & $\begin{array}{l}\text { Need for blood } \\
\text { transfusion }\end{array}$ \\
\hline PCI-Trial & 202 & $23-29$ & $\begin{array}{l}\text { Resuscitation } \\
\text { if needed }\end{array}$ & $\begin{array}{l}\text { Intact cord } \\
\text { milking } \times 4\end{array}$ & $3 \mathrm{~min}$ & $\begin{array}{c}\text { composite outcome } \\
\text { of severe IVH, } \\
\text { chronic lung disease } \\
\text { or death }\end{array}$ \\
\hline
\end{tabular}

Ashish et al. have recently completed a single center trial in Nepal (Nep-Cord 3 trial, $n=231$, NCT02727517) in depressed term neonates to compare delayed cord clamping of greater than $180 \mathrm{~s}$ with resuscitation with early cord clamping $(<60 \mathrm{~s})$. The primary hypothesis is that delayed cord clamping improves oxygen saturation, heart rate, and Apgar scores in the first $10 \mathrm{~min}$ of life compared to early cord clamping.

Blank et al. are conducting a similar study (Baby DUCC, Australian Trial Registry \#12618000621213) in non-vigorous infants $(n=120)$ greater than or equal to 32 weeks gestational age. Infants will receive delayed cord clamping with resuscitation until at least 1 minute after the colorimetric $\mathrm{CO} 2$ detector has indicated gas exchange or at $5 \mathrm{~min}$ of life they will receive immediate cord clamping. The primary outcome in this trial will be the heart rate at 60 and $120 \mathrm{~s}$. The trial has enrolled 30 infants and is expected to be completed in 2021 (personal communication).

Knol et al. are conducting a multicenter trial of time-based clamping ( $n=660$, ABC2 NCT03808051) 30-60 s after delivery depending on the condition of the infant) compared to physiological-based cord clamping in infants less than 30 weeks gestation. The outcome is a composite outcome of intact survival (survival without grade 2 IVH or higher, or necrotizing enterocolitis).

Nevill et al. are studying preterm infants that are not breathing well by $15 \mathrm{~s}$ of life and randomizing them to breathing assistance or just stimulation until $60 \mathrm{~s}$ of life. The primary outcome is the need for a blood transfusion.

Lastly, Pratesi et al. are proposing a multicenter trial (PCI-Trial, NCT02671305) comparing intact umbilical cord milking to delayed cord clamping for $3 \mathrm{~min}$ with assistance when needed in premature infants $<30$ weeks. Their primary outcome is a composite outcome of severe IVH, BPD, and death with a sample size of 202 infants.

\section{Challenges with Resuscitation with an Intact Cord}

There have been two surveys to report parental and provider assessments of performing resuscitation with an intact cord. Thomas et al. evaluated term and preterm newborns that received resuscitation with an intact cord [20]. The majority of clinicians in their study (86\%) rated the resuscitation trolley as the "same", "better", or "much better" than conventional equipment. In a second survey involving term infants done by our group, we found that only $41 \%$ of neonatal providers and $32 \%$ of maternal providers found the process of resuscitation with an intact cord as positive or strongly positive [21]. One-third felt that the cord was too short for access and they had poor access to the baby. Twenty-five percent also felt that they had difficulty accessing equipment. On the other hand, for both surveys, the majority of parents felt that the experience of bedside resuscitation was positive. 
This was probably because they were able to visualize and or touch their newborn immediately after delivery and throughout the resuscitation.

In practice, many of these concerns are still a challenge. With many of our studies on resuscitation with an intact cord currently facing challenges with maintaining a sterile field (there is not a commercially available sterile T-piece), providing adequate temperature (a chemical mattress had to be used on top of the resuscitation bed), and only one provider had access to equipment. A patient could not have oxygen or ventilator pressures easily adjusted. In addition, there was not an available display for monitoring the patient viewable to the provider. A new purpose-built resuscitation table has been developed to attempt to overcome some of these issues [15].

\section{Conclusions}

Neonatal resuscitation with an intact cord is an exciting possibility to ensure every newborn receives a placental transfusion. Several important clinical trials in both term and preterm infants will help answer the question as to its clinical benefit. There are a number of logistical issues that will need to be improved before this becomes standard practice, but it holds tremendous promise.

Funding: This research received no external funding.

Conflicts of Interest: The authors declare no conflict of interest.

\section{References}

1. Andersson, O.; Lindquist, B.; Lindgren, M.; Stjernqvist, K.; Domellof, M.; Hellstrom-Westas, L. Effect of delayed cord clamping on neurodevelopment at 4 years of age: A randomized clinical trial. JAMA Pediatr. 2015, 169, 631-638. [CrossRef]

2. Tarnow-Mordi, W.; Morris, J.; Kirby, A.; Robledo, K.; Askie, L.; Brown, R.; Evans, N.; Finlayson, S.; Fogarty, M.; Gebski, V.; et al. Delayed versus immediate cord clamping in preterm infants. N. Engl. J. Med. 2017. [CrossRef]

3. Fogarty, M.; Osborn, D.A.; Askie, L.; Seidler, A.L.; Hunter, K.; Lui, K.; Simes, J.; Tarnow-Mordi, W. Delayed vs early umbilical cord clamping for preterm infants: A systematic review and meta-analysis. Am. J. Obstet. Gynecol. 2018, 218, 1-18. [CrossRef]

4. Redmond, A.; Isana, S.; Ingall, D. Relation of onset of respiration to placental transfusion. Lancet 1965, 1, 283-285. [CrossRef]

5. Philip, A.G.; Yee, A.B.; Rosy, M.; Surti, N.; Tsamtsouris, A.; Ingall, D. Placental transfusion as an intrauterine phenomenon in deliveries complicated by foetal distress. Br. Med. J. 1969, 2, 11-13. [CrossRef] [PubMed]

6. Vyas, H.; Milner, A.D.; Hopkins, I.E. Intrathoracic pressure and volume changes during the spontaneous onset of respiration in babies born by cesarean section and by vaginal delivery. J. Pediatr. 1981, 99, 787-791. [CrossRef]

7. Katheria, A.C.; Lakshminrusimha, S.; Rabe, H.; McAdams, R.; Mercer, J.S. Placental transfusion: A review. J. Perinatol. 2017, 37, 105-111. [CrossRef]

8. Ersdal, H.L.; Linde, J.; Mduma, E.; Auestad, B.; Perlman, J. Neonatal outcome following cord clamping after onset of spontaneous respiration. Pediatrics 2014, 134, 265-272. [CrossRef]

9. Nevill, E.; Meyer, M.P. Effect of delayed cord clamping (dcc) on breathing and transition at birth in very preterm infants. Early Hum. Dev. 2015, 91, 407-411. [CrossRef] [PubMed]

10. Bhatt, S.; Alison, B.J.; Wallace, E.M.; Crossley, K.J.; Gill, A.W.; Kluckow, M.; te Pas, A.B.; Morley, C.J.; Polglase, G.R.; Hooper, S.B. Delaying cord clamping until ventilation onset improves cardiovascular function at birth in preterm lambs. J. Physiol. 2013, 591, 2113-2126. [CrossRef] [PubMed]

11. Bhatt, S.; Polglase, G.R.; Wallace, E.M.; Te Pas, A.B.; Hooper, S.B. Ventilation before umbilical cord clamping improves the physiological transition at birth. Front. Pediatr. 2014, 2, 113. [CrossRef]

12. Richardson, D.K.; Phibbs, C.S.; Gray, J.E.; McCormick, M.C.; Workman-Daniels, K.; Goldmann, D.A. Birth weight and illness severity: Independent predictors of neonatal mortality. Pediatrics 1993, 91, 969-975. [CrossRef] 
13. Winter, J.; Kattwinkel, J.; Chisholm, C.; Blackman, A.; Wilson, S.; Fairchild, K. Ventilation of preterm infants during delayed cord clamping (ventfirst): A pilot study of feasibility and safety. Am. J. Perinatol. 2017, 34, 111-116. [CrossRef]

14. Blank, D.A.; Badurdeen, S.; Omar, F.K.C.; Jacobs, S.E.; Thio, M.; Dawson, J.A.; Kane, S.C.; Dennis, A.T.; Polglase, G.R.; Hooper, S.B.; et al. Baby-directed umbilical cord clamping: A feasibility study. Resuscitation 2018, 131, 1-7. [CrossRef]

15. Knol, R.; Brouwer, E.; Vernooij, A.S.N.; Klumper, F.J.C.M.; DeKoninck, P.; Hooper, S.B.; te Pas, A.B. Clinical aspects of incorporating cord clamping into stabilisation of preterm infants. Arch. Dis. Child Fetal. Neonatal. Ed. 2018, 103, 493-497. [CrossRef] [PubMed]

16. Pratesi, S.; Montano, S.; Ghirardello, S.; Mosca, F.; Boni, L.; Tofani, L.; Dani, C. Placental circulation intact trial (PCI-T) - resuscitation with the placental circulation intact vs. Cord milking for very preterm infants: A feasibility study. Front. Pediatr. 2018, 6. [CrossRef] [PubMed]

17. Duley, L.; Dorling, J.; Pushpa-Rajah, A.; Oddie, S.J.; Yoxall, C.W.; Schoonakker, B.; Bradshaw, L.; Mitchell, E.J.; Fawke, J.A. Randomised trial of cord clamping and initial stabilisation at very preterm birth. Arch. Dis. Child Fetal. Neonatal. Ed. 2017. [CrossRef]

18. Katheria, A.; Poeltler, D.; Durham, J.; Steen, J.; Rich, W.; Arnell, K.; Maldonado, M.; Cousins, L.; Finer, N. Neonatal resuscitation with an intact cord: A randomized clinical trial. J. Pediatr. 2016, 178, 75-80. [CrossRef]

19. Katheria, A.C.; Brown, M.K.; Faksh, A.; Hassen, K.O.; Rich, W.; Lazarus, D.; Steen, J.; Daneshmand, S.S.; Finer, N.N. Delayed cord clamping in newborns born at term at risk for resuscitation: A feasibility randomized clinical trial. J. Pediatr. 2017, 187, 313-317. [CrossRef]

20. Thomas, M.R.; Yoxall, C.W.; Weeks, A.D.; Duley, L. Providing newborn resuscitation at the mother's bedside: Assessing the safety, usability and acceptability of a mobile trolley. BMC Pediatr. 2014, 14, 135. [CrossRef] [PubMed]

21. Katheria, A.C.; Sorkhi, S.R.; Hassen, K.; Faksh, A.; Ghorishi, Z.; Poeltler, D. Acceptability of bedside resuscitation with intact umbilical cord to clinicians and patients' families in the united states. Front. Pediatr. 2018, 6, 100. [CrossRef] 